\section{(6) OPEN ACCESS}

\title{
The phenotype of TNF receptor-associated autoinflammatory syndrome (TRAPS) at presentation: a series of 158 cases from the Eurofever/EUROTRAPS international registry
}

\author{
H J Lachmann, ${ }^{1}$ R Papa, ${ }^{2} \mathrm{~K}$ Gerhold, ${ }^{3}$ L Obici, ${ }^{4}$ । Touitou, ${ }^{5}$ L Cantarini, ${ }^{6}$ J Frenkel, ${ }^{7}$ \\ J Anton, ${ }^{8}$ I Kone-Paut, ${ }^{9}$ M Cattalini, ${ }_{10}^{10}$ B Bader-Meunier, ${ }^{11}$ A Insalaco, ${ }^{12} \mathrm{~V} \mathrm{Hentgen,}^{13}$ \\ R Merino, ${ }^{14} \mathrm{C}$ Modesto, $^{15} \mathrm{~N}$ Toplak, ${ }^{16} \mathrm{R}$ Berendes, $^{17} \mathrm{~S}$ Ozen, ${ }^{18} \mathrm{R} \mathrm{Cimaz}^{19}$ \\ A Jansson, ${ }^{20}$ P A Brogan, ${ }^{21}$ P N Hawkins, ${ }^{1}$ N Ruperto, ${ }^{2}$ A Martini, ${ }^{22}$ P Woo, ${ }^{21}$ \\ M Gattorno, ${ }^{2}$ for the Paediatric Rheumatology International Trials Organisation \\ (PRINTO), the EUROTRAPS and the Eurofever Project
}

\section{Handling editor Tore K Kvien \\ For numbered affiliations see end of article.}

\section{Correspondence to} Dr Helen J Lachmann, Division of Medicine, National Amyloidosis Centre, UCL Medical School, Royal Free Campus, Rowland Hill Street, London NW3 2PF, UK; h.lachmann@ucl.ac.uk

Received 26 June 2013 Revised 23 July 2013 Accepted 27 July 2013 Published Online First 21 August 2013

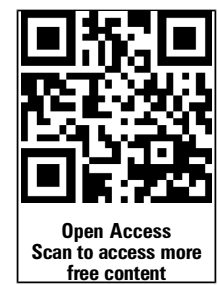

CrossMark

To cite: Lachmann $\mathrm{HJ}$ Papa R, Gerhold K, et al. Ann Rheum Dis

2014;73:2160-2167.

\section{ABSTRACT}

Objective To evaluate the genetic findings, demographic features and clinical presentation of tumour necrosis factor receptor-associated autoinflammatory syndrome (TRAPS) in patients from the Eurofever/ EUROTRAPS international registry.

Methods A web-based registry collected retrospective data on patients with TNFRSF1A sequence variants and inflammatory symptoms. Participating hospitals included paediatric rheumatology centres and adult centres with a specific interest in autoinflammatory diseases. Cases were independently validated by experts in the disease.

Results Complete information on 158 validated patients was available. The most common TNFRSF1A variant was R92Q (34\% of cases), followed by T50M (10\%). Cysteine residues were disrupted in $27 \%$ of cases, accounting for $39 \%$ of sequence variants. A family history was present in 19\% of patients with R92Q and $64 \%$ of those with other variants. The median age at which symptoms began was 4.3 years but $9.1 \%$ of patients presented after 30 years of age. Attacks were recurrent in $88 \%$ and the commonest features associated with the pathogenic variants were fever $(88 \%)$, limb pain $(85 \%)$, abdominal pain (74\%), rash (63\%) and eye manifestations (45\%). Disease associated with R92Q presented slightly later at a median of 5.7 years with significantly less rash or eye signs and more headaches. Children were more likely than adults to present with lymphadenopathy, periorbital oedema and abdominal pains. AA amyloidosis has developed in $16(10 \%)$ patients at a median age of 43 years.

Conclusions In this, the largest reported case series to date, the genetic heterogeneity of TRAPS is accompanied by a variable phenotype at presentation. Patients had a median 70 symptomatic days a year, with fever, limb and abdominal pain and rash the commonest symptoms. Overall, there is little evidence of a significant effect of age or genotype on disease features at presentation.

\section{INTRODUCTION}

The tumour necrosis factor receptor-associated periodic fever syndrome (TRAPS) was first described as familial Hibernian fever in $1982^{1}$ but was renamed after the discovery that it is associated with mutations in the gene for tumour necrosis factor receptor superfamily member $1 \mathrm{~A}$ (TNFRSF1A), on chromosome $12.2^{3}$ It is now recognised as one of the hereditary recurrent fever syndromes, a group of autoinflammatory diseases caused by inappropriate activity of the innate immune system. ${ }^{4}{ }^{5}$ Most sequence variants (SVs) underlying TRAPS lie within exons 2 to 4 , and there appears to be over-representation of missense substitutions which disrupt structurally important cysteine-cysteine disulfide bonds in the extracellular domain (Infevers database: http://fmf.igh.cnrs.fr/ ISSAID/infevers/). ${ }^{6-8}$ The mechanism(s) by which heterozygous TNFRSF1A SVs cause TRAPS remain (s) unclear and probably differ(s) between variants. $^{9-13}$ The two commonest TNFRSF1A variants, P46L and R92Q, which are only associated with symptoms in a minority of people, are present in about $10 \%$ of West Africans and 2\% of Caucasians, respectively. ${ }^{14}$ There is haplotype evidence of a common founder in $\mathrm{R}^{2} 2 \mathrm{Q}^{5}$ and it may be a minor susceptibility factor for development of multiple sclerosis. ${ }^{15}$ The vast majority of carriers of these two variants are entirely well, and how they cause inflammatory disease in a minority remains obscure.

TRAPS is a very rare disease with an estimated prevalence of about one per million. ${ }^{16}$ It has been more frequently reported in Caucasians but whether this reflects true increased incidence or ascertainment bias is uncertain. TRAPS is a far less distinct disease entity than familial Mediterranean fever; attacks can be discrete or near continuous and are often prolonged, lasting several weeks and accompanied by a variety of features, including fever, abdominal pain, rash, eye manifestations, headache, pleuritic pain and lymphadenopathy. ${ }^{5}$ Symptoms are almost universally accompanied by a marked acute phase response and leucocytosis.

Diagnosis relies on clinical suspicion supported by genetic testing, but this has been severely ham- 
pered by the absence of any large-scale description of disease manifestations and by the absence of any validated diagnostic criteria. ${ }^{17}$ To further complicate the diagnosis, it is not known whether clinical features vary with age and thus if the disease presents differently in children. It is also unknown whether features at presentation predict the subsequent course of the disease and complications, or whether there is genotype-phenotype correlation in relation to clinical presentation and/or severity.

The combined European Union-funded projects of Eurofever and EUROTRAPS sought to answer these questions by collecting data on large numbers of patients in a common registry. ${ }^{18}$ We here describe the clinical manifestations at presentation in 158 patients, of whom 53 were children (aged $<18$ at data collection) and 105 adults.

\section{PATIENTS AND METHODS}

The data analysed in this study were extracted from the Eurofever/EUROTRAPS registry (EAHC project numbers: 2007332 and 200923), which has been enrolling since November 2009. ${ }^{18} 19$ Ethical committee approval for entering patients in the registry and informed consent or assent was obtained in the participating countries according to local regulatory requirements.

Inclusion criteria were symptomatic inflammatory disease associated with a TNFRSF1A variant. Demographic information, clinical manifestations and laboratory findings at presentation were collected. Information about molecular genetic analysis was also collected, including the sequence variants found (Infevers database, http://fmf.igh.cnrs.fr/ISSAID/infevers/). Clinical details were sought about the features at disease onset rather than at diagnosis and included (i) characteristics of fever episodes (duration, frequency, triggers, etc), (ii) presence and frequency (always or often/sometimes) of clinical manifestations. All completed cases were anonymously and independently validated by at least one expert in the disease (HJL, PW, MG) in order to confirm the diagnosis. This analysis includes all cases validated before June 2012 .

\section{Statistics}

Frequencies and percentages were used as descriptive statistics for categorical variables. To describe numerical variables median and range were used. Differences among groups were assessed by Mann-Whitney U test or Kruskal-Wallis test when evaluating continuous variables and by $\chi^{2}$ tests for discrete variables. Post hoc analysis between groups was performed by Mann-Whitney $\mathrm{U}$ test or $\chi^{2}$ test; no adjustments for multiple comparisons were performed. In order to analyse the clinical phenotype of the patients according to the type of gene variants, we divided the patients into three subgroups: (A) patients carrying cysteine or T50M variants, (B) patients with other variants and (C) patients with the low-penetrance variants R92Q and P46L.

\section{RESULTS}

\section{Demographic data}

In June 2012, 224 patients with TRAPS were available in the registry. Of these, 59 patients were excluded as only baseline demographic data without clinical information were available, and seven patients were excluded at the validation stage. None of these had mutations detected in TNFRSF1A, four had no specific symptoms, one responded well to broad-spectrum immunosuppressant agents with extremely short attacks of systemic inflammation, one had recurrent pericarditis and the final patient had a new NLRP3 mutation and non-specific mild symptoms. A total of 158 analysed patients were enrolled by 18 centres in 11 countries. All patients but one were enrolled by European centres: UK (64 patients), Italy (38), France (17), Germany (16), Spain (8), Netherlands (6), Ireland (4), Greece (2), Slovenia (1) and Turkey (1). One patient born in the UK was enrolled in Australia. Eight patients had immigrated to the country of the referral centre and originated from Portugal, Slovakia, Canada, the Congo, Nigeria, Mauritius, Kuwait and Iraq. Most of the patients $(147,93 \%)$ were European Caucasians. Four were Arab originating from the Middle East or North Africa; three were sub-Saharan African and two South Asians. Two patients had a mixed origin: Caucasian/Asian and Caucasian/African, respectively.

Demographic details are summarised in table 1 . The median age at enrolment was 33.8 years (range $3-77)$. The majority of the patients were adults $(105,66 \%)$. Fifty-three patients $(34 \%)$ were children or adolescents aged $<18$ years. Across the whole cohort the median age at symptom onset was 4.3 years (range $0.2-63$ ); it was 4 years (range 0-49) in patients with a SV and a median of 5.7 years (range 0-53) in patients with R92Q (not significant). Development of symptoms after the age of 30 years was seen in $9.1 \%$ of patients with no difference between those with low-penetrant variants and those carrying other SVs. Median disease duration at enrolment was 15.6 years, in the children it was 6.6 years and in adults 27.7 years. The median age at diagnosis with TRAPS for the whole group was 25.9 years; children were diagnosed at 6.2 years; whereas diagnosis in adults was at a median of 37.9 years, reflecting a median diagnostic delay of 10.3 years, which was almost 10 times higher than in the study paediatric patients.

\section{Genotypic characterisation}

All patients had SVs in TNFRSF1A. Sequencing of the whole gene was performed in nine patients $(6 \%)$ and a search for a single mutation was performed in five patients $(3 \%)$. In the majority of patients $(134,85 \%)$ selected exons, mainly from 1 to 4 , had been analysed. In total 46 variants were found, the complete list is reported in table 2 . The vast majority of the patients were heterozygous for missense mutations involving exon 2 (29 patients), exon 3 (59 patients) and exon 4 (64 patients). Five patients carried variants in non-coding intronic regions of the gene. One patient displayed a large deletion in exon 6. Only 19 variants $(41.3 \%)$ were identified in more than one unrelated individual.

Table 1 Demographic characteristics of patients with TRAPS at the time of enrolment

\begin{tabular}{lccc}
\hline Characteristics & $\begin{array}{l}\text { Whole TRAPS } \\
\text { population }\end{array}$ & $\begin{array}{l}\text { Paediatric } \\
\text { patients }\end{array}$ & $\begin{array}{l}\text { Adult } \\
\text { patients }\end{array}$ \\
\hline Number of patients & 158 & 53 & 105 \\
Male:female & $78: 80$ & $31: 22$ & $47: 58$ \\
Age at onset (years) & $4.3(0-63)$ & $1.5(0-13)$ & $8(0-63)$ \\
Age at diagnosis (years) & $25.9(0-77)$ & $6.2(0-15)$ & $37.9(1-77)$ \\
Age at enrolment (years) & $33.8(3-77)$ & $11.2(3-18)$ & $42.3(19-77)$ \\
Diagnostic delay (years) & $10.3(0-77)$ & $2.7(0-14)$ & $22.4(0-77)$ \\
Disease duration (years) & $15.6(1-77)$ & $6.6(1-17)$ & $27.7(1-77)$ \\
$\begin{array}{l}\text { Disease onset at } \\
<18 \text { years, } n \text { (\%) }\end{array}$ & $123(78)$ & 53 & $70(67)$ \\
Disease onset aged & $35(22)$ & - & $35(33)$ \\
$\geq 18$ years, $\mathrm{n}$ (\%) & & & \\
\hline \multicolumn{2}{l}{ Results are shown as median (range) unless stated otherwise. }
\end{tabular}


Table 2 The TNFRSF1A variants in the 158 patients

\begin{tabular}{|c|c|c|c|}
\hline Variant (protein variant) & Location & Number of cases (\%) & Ethnicity \\
\hline D12E (p.Asp41Glu) & Exon 2 & $3(2)$ & Caucasian \\
\hline H22Q (p.His51Gln) & & $2(1)$ & Caucasian \\
\hline H22R (p.His51Arg) & & $3(2)$ & Caucasian \\
\hline C29F (p.Cys58Phe) & & $1(0.5)$ & Caucasian \\
\hline C29Y (p.Cys58Tyr) & & $1(0.5)$ & Asian \\
\hline C30F (p.Cys59Phe) & & $1(0.5)$ & Caucasian \\
\hline C30R (p.Cys59Arg) & & $4(3)$ & Caucasian \\
\hline C30Y (p.Cys59Tyr) & & $1(0.5)$ & Caucasian \\
\hline C33G (p.Cys62Gly) & & $1(0.5)$ & Arab \\
\hline C33Y (p.Cys62Tyr) & & $12(8)$ & Caucasian \\
\hline c. $193-14 G>A$ & Intron 2 & $1(0.5)$ & Caucasian \\
\hline c.194-15C>T & & $1(0.5)$ & Caucasian \\
\hline \multirow[t]{2}{*}{ T37I (p.Thr66lle) } & Exon 3 & $2(1)$ & Arab \\
\hline & & $1(0.5)$ & Caucasian \\
\hline Y38S (c.200A>C) & & $1(0.5)$ & Caucasian \\
\hline L39F (p.Leu68Phe) & & $4(3)$ & Caucasian \\
\hline D42DEL (p.Asp71del) & & $1(0.5)$ & Caucasian \\
\hline $\mathrm{C} 43 \mathrm{G}(\mathrm{c} 214 \mathrm{~T}>\mathrm{G})$ & & $3(2)$ & Caucasian \\
\hline C43R (p.Cys72Arg) & & $1(0.5)$ & Caucasian \\
\hline C43S (p.Cys72Ser) & & $1(0.5)$ & Caucasian \\
\hline C43Y (p.Cys72Tyr) & & $5(3)$ & Arab, Sub-Saharan African $\times 2$, Caucasian $\times 2$ \\
\hline \multirow[t]{2}{*}{ P46L (p.Pro75Leu) } & & & Caucasian \\
\hline & & & Caucasian $\times 15$, African $\times 1$ \\
\hline T50K (p.Thr79Lys) & & $2(1)$ & Caucasian Caucasian $\times 3$, Arab $\times 1$ \\
\hline \multirow[t]{2}{*}{ T50M (p.Thr79Met) } & & $16(10)$ & Caucasian \\
\hline & & & Caucasian \\
\hline C52Y (p.Cys81Tyr) & & $5(3)$ & Caucasian \\
\hline \multirow[t]{2}{*}{ C55Y (p.Cys84Tyr) } & & $4(3)$ & Caucasian \\
\hline & & & Caucasian \\
\hline S59P (p.Ser88Pro) & & $1(0.5)$ & Caucasian \\
\hline F60L (p.Phe89Leu) & & $2(1)$ & Caucasian \\
\hline T61N (p.Thr90Asn) & & $2(1)$ & \\
\hline N65I (p.Asn94lle) & & $2(1)$ & Caucasian \\
\hline H66L (p.His95Leu) & & $1(0.5)$ & Caucasian \\
\hline L67P (p.Leu96Pro) & & $1(0.5)$ & \\
\hline H69fs (p.His98_Cys99delinsArg) & & $1(0.5)$ & \\
\hline \multicolumn{4}{|l|}{ C73R (p.Cys102Arg) } \\
\hline \multirow[t]{2}{*}{ C73W (p.Cys102Trp) } & & $1(0.5)$ & \\
\hline & & $2(1)$ & \\
\hline C88Y (p.Cys117Tyr) & Exon 4 & $1(0.5)$ & Caucasian \\
\hline R92P (p.Arg121Pro) & & $1(0.5)$ & Caucasian \\
\hline R92Q (p.Arg121Gln) & & $54(34)$ & Caucasian \\
\hline V95M (p.Val124Met) & & $2(1)$ & Caucasian \\
\hline C96Y (p.Cys125Tyr) & & $1(0.5)$ & Caucasian \\
\hline Y103_R104DEL (p.Tyr132_Arg133del) & & $1(0.5)$ & Caucasian \\
\hline \multicolumn{4}{|l|}{ E109A (p.Glu138Ala) } \\
\hline C114W (p.Cys143Trp & & $2(1)$ & Caucasian \\
\hline \multirow[t]{2}{*}{ N116S (p.Asn145Ser) } & & $1(0.5)$ & Caucasian \\
\hline & & $1(0.5)$ & Caucasian \\
\hline$c .472+6 C>T$ & Intron 4 & $2(1)$ & Caucasian \\
\hline L167_G175del (c.586_612del127 & Exon 6 & $1(0.5)$ & Asian \\
\hline Intronic substitution $c 626-32 \mathrm{G}>\mathrm{T}$ & Intron 6 & $1(0.5)$ & Caucasian \\
\hline
\end{tabular}

The distribution of the genotype according to age and disease onset is shown in table 3 . T50M was the single commonest variant, found in 16 patients including five unrelated kindreds from five different countries. Eighteen different variants involving cysteine residues were found in 42 patients. In 30 patients (19\%) other missense variants previously reported to be associated with a TRAPS phenotype were seen (Infevers: http:// fmf.igh.cnrs.fr/ISSAID/infevers/); another 12 patients carried variants for which the association with the clinical phenotype had not previously been considered certain. The low-penetrant variants, R92Q and P46L, were found in 54 and five patients, respectively. Four of the $\mathrm{P} 46 \mathrm{~L}$ cases also had sequencing of 
Table 3 Major groups of genetic variants in the different age groups of patients with TRAPS

\begin{tabular}{llllr}
\hline & $\begin{array}{l}\text { Whole TRAPS population } \\
\text { Number (\%) }\end{array}$ & $\begin{array}{l}\text { Paediatric patients } \\
\text { Number (\%) }\end{array}$ & $\begin{array}{l}\text { Adults with paediatric onset } \\
\text { Number (\%) }\end{array}$ & $\begin{array}{l}\text { Adults with adult onset } \\
\text { Number (\%) }\end{array}$ \\
\hline Sequence variants involving a cysteine residue or T50M & $58(37)$ & $14(26)$ & $26(37)$ & $8(23)$ \\
Other sequence variants & $41(26)$ & $12(23)$ & $19(27)$ & $10(29)$ \\
R92Q or P46L & $59(37)$ & $27(51)$ & $15(21)$ & $17(49)$ \\
Total number of patients (\% of total) & $158(100)$ & $53(34)$ & $70(44)$ & $35(22)$ \\
\hline
\end{tabular}

additional fever genes; $M E F V$ in three cases, and MEFV, NLRP3 and $M V K$ in the other with no variants found. Of the patients carrying R92Q, 24 patients underwent additional sequencing: $M E F V$ in 22 cases, MVK in 11 and NLRP3 in two. Two patients were found to carry $M E F V$ variants, one case each of E148Q and R121Q.

In adult patients a SV involving T50M or a cysteine residue was seen in 26 (51\%) of those with disease onset in childhood and eight patients $(22.9 \%)$ with an adult onset $(\mathrm{p}<0.001)$. Conversely, in the adults in this study the prevalence of the lowpenetrant variants, R92Q and P46L, was twice as high in those with an adult onset $(49 \%)$ compared with those with a paediatric onset $(21 \%)(\mathrm{p}<0.001)$. In paediatric patients the distribution of mutation types was similar to that seen in adult-onset TRAPS (table 3). A family history of TRAPS was reported by 11 (19\%) patients with the lower-penetrance R92Q variant. In patients with other SVs $64 \%$ had a suggestive family history, and this was exactly the same in the subgroup of T50M and variants involving a cysteine residue.

\section{Clinical features at presentation}

At presentation 139 patients (88\%) reported that their symptoms occurred in recurrent episodes and only $11(7 \%)$ had continuous symptoms (three C33Y, two C73W, five R92Q, one $\mathrm{P} 46 \mathrm{~L}$ ) (table 4). In the remaining eight patients disease was continuous with episodic flares. The disease burden was high with an average of 70 symptomatic days a year. Median attack duration was 10.8 days for the whole cohort with no significant differences in the duration or number of attacks between the paediatric and adult populations. There was considerable variation in attack duration with a third of attacks lasting less than a week, shorter attacks were more frequent in patients with lowpenetrance SVs, accounting for $40 \%$ compared with $26 \%$ in patients with mutations affecting T50M or cysteine residues $(\mathrm{p}<0.05)$ (figure 1$)$. Only $12 \%$ of patients reported regular predictable attacks, but these were commoner in paediatric patients than in adults $(26.4 \%$ and $4.8 \%$ respectively, $\mathrm{p}<0.05)$. Just over a quarter of patients (40 cases) could identify triggers for their attacks. The commonest reported triggers were emotional stress (21 patients); menstrual cycle (17); fatigue (10); infections (9); exercise (7) and vaccinations (6). There were no significant differences between the incidence and type of triggers in children and adults except for the entirely explicable findings that vaccination and infections were reported more commonly in children (who are more exposed to them) and the menstrual cycle in females after menarche. A fever of $>38^{\circ} \mathrm{C}$ was reported by

Table 4 Characteristics of fever episodes according to the age and disease onset

\begin{tabular}{|c|c|c|c|c|}
\hline Number of patients & $\begin{array}{l}\text { Whole TRAPS population } \\
(n=158) \\
\text { Number }(\%)\end{array}$ & $\begin{array}{l}\text { Paediatric patients } \\
(\mathrm{n}=53) \\
\text { Number }(\%)\end{array}$ & $\begin{array}{l}\text { Adults with paediatric onset } \\
(\mathrm{n}=70) \\
\text { Number }(\%)\end{array}$ & $\begin{array}{l}\text { Adults with adult onset } \\
(n=35) \\
\text { Number (\%) }\end{array}$ \\
\hline \multicolumn{5}{|l|}{ Disease course } \\
\hline Recurrent* & $139(88)$ & $48(91)$ & $57(81)$ & $34(97)$ \\
\hline Continuoust & $11(7)$ & $4(8)$ & $6(9)$ & $1(3)$ \\
\hline Continuous with flares & $8(5)$ & $1(2)$ & $7(10)$ & 0 \\
\hline \multicolumn{5}{|c|}{ Characteristics of the disease episodes } \\
\hline \multicolumn{5}{|c|}{ Duration } \\
\hline$>14$ days & $32(25)$ & $10(24)$ & $14(24)$ & $8(27)$ \\
\hline $7-14$ days & $55(43)$ & $18(43)$ & $26(46)$ & $11(37)$ \\
\hline$<7$ days & $42(33)$ & $14(33)$ & $17(29)$ & $11(37)$ \\
\hline Mean duration (days) & 10.8 & 10.7 & 10.9 & 10.9 \\
\hline Mean number of episodes/year & 7.7 & 7.7 & 7.6 & 6.9 \\
\hline Fever $\left(>38^{\circ} \mathrm{C}\right)$ & $132(84)$ & $48(91)$ & $56(80)$ & $28(80)$ \\
\hline Low-grade fever $\left(<38^{\circ} \mathrm{C}\right)$ & $57(36)$ & $16(30)$ & $27(39)$ & $14(40)$ \\
\hline Rigours/chills at fever onset & $48(30)$ & $18(34)$ & $25(36)$ & $5(14)$ \\
\hline \multicolumn{5}{|l|}{ Pattern of attacks } \\
\hline Irregular & $91(58)$ & $32(60)$ & $39(56)$ & $20(57)$ \\
\hline Regular & $19(12)$ & $14(26)$ & $4(6)$ & $1(3)$ \\
\hline Seasonal changes & $4(2.5)$ & $1(3)$ & $3(4)$ & 0 \\
\hline Triggers & $40(25)$ & $15(28)$ & $19(27)$ & $6(17)$ \\
\hline
\end{tabular}

* Recurrent manifestations with disease-free intervals.

tContinuous/subchronic manifestations with possible episodic flares. 


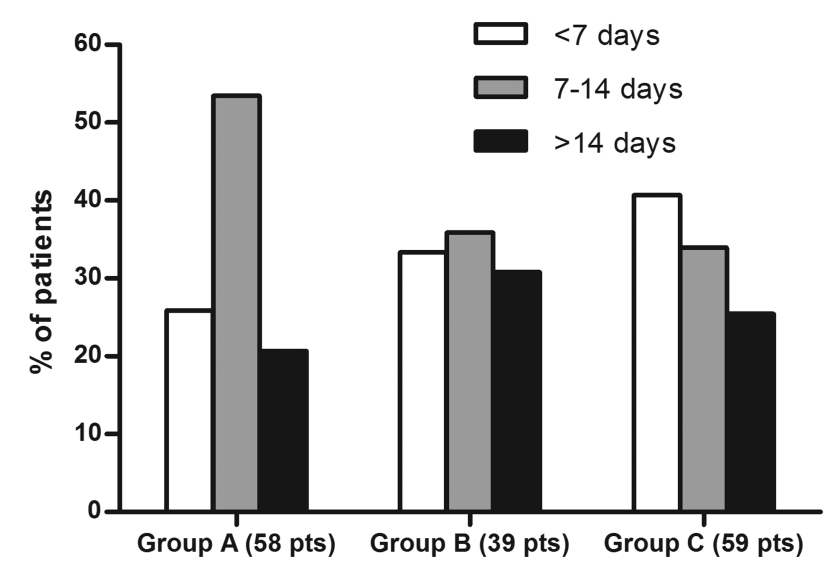

Figure 1 Duration of the episodes according to the major groups of genetic variants in patients with TRAPS expressed as a percentage of attacks. Group A patients carry a sequence variant involving a cysteine residue or T50M; group B patients carry other sequence variants; group C patients carry R92Q or P46L.

$83.5 \%$ of patients with no difference between adult and paediatric cases, and rigours occurred in 30\%.

The most common symptoms accompanying episodes are reported in table 5. The dominant classes of symptoms: fever, limb pain, abdominal pain and rash were seen in $88 \%, 85 \%$, $74 \%$ and $63 \%$ of patients with clear-cut variants; and $94 \%$, $79 \%, 64 \%$ and $30 \%$ of patients with the R92Q variant, respectively. Periorbital oedema, a pathognomic feature of TRAPS was seen in $20 \%$ of the whole cohort. Comparison of the different variant groups ((A) variants affecting cysteine residues and T50M, (C) the low-penetrance variants R92Q and P46L and (B) all other SVs) showed remarkably few differences which reached significance. Patients in groups $\mathrm{A}$ and $\mathrm{B}$ were more likely than patients with R92Q to have a rash $(63 \%$ vs $30 \%$ $(\mathrm{p}<0.001))$ and eye symptoms $(45 \%$ vs $26 \% \quad(\mathrm{p}<0.05))$. Patients with R92Q had significantly more headaches $(40 \%$ vs $13 \%(\mathrm{p}<0.001)$ and a non-significant trend towards more oropharyngeal symptoms (30\% vs 19\%) (table 5).

A comparison of patients who presented in childhood (the 53 paediatric patients and 70 adult patients with childhood onset) with the 30 adult patients (with first symptoms after the age of 18 years) showed that the only significant differences were cervical lymphadenopathy, which was present in $31 \%$ of attacks presenting in childhood and $9 \%$ of adults; periorbital oedema and abdominal pain were also commoner in childhood presentation occurring in $24 \%$ and $74 \%$, respectively $(p<0.05)$. Only chest pain with attacks was significantly more frequent in adult presentation, occurring in 54\% compared with $20 \%$ in childhood $(\mathrm{p}<0.05)$; in general, chest pain was most frequent in patients with T50M (6/16 cases), although they reported neither pericarditis nor pleurisy (table 5).

AA amyloidosis occurred in 16 cases $(10 \%)$ at a median age of 43 years (range 20-77). This group included seven cysteine variants (44\%), two T50M (13\%) and no patients with R92Q. Patients who developed AA amyloidosis had significantly longer disease duration than those who did not (39 vs 19.4 years $(p<0.001)$ and 13 of the 16 cases had their first symptoms in childhood.

\section{DISCUSSION}

This is the largest reported series of patients with symptoms and confirmed variants in the TNFRSF1A gene and shows the strength of international cooperation in the study of an extremely uncommon condition which can present to a wide variety of specialties, and to both paediatric and adult services. The diagnosis of very rare diseases relies on a high 'index of suspicion' followed by specific testing. In diseases where the diagnostic test is both expensive and of limited availability we hope that definition of what constitutes a 'target group' will facilitate early recognition of probable cases and appropriate use of limited resources. These results show that TRAPS is a pleiomorphic condition characterised by attacks of fever in $>83 \%$ accompanied by symptoms including diffuse limb pain, abdominal pain and rash. In many respects our data confirm the case descriptions from earlier publications, ${ }^{5} 20-24$ but it is also important to recognise that by no means all patients fall into a tightly circumscribed phenotype. In particular, despite its autosomal dominant nature, a family history of TRAPS is reported by fewer than two-thirds of patients, and symptoms begin after the age of 18 years in $22 \%$. In addition, although the average disease attack lasts for $>10$ days, 30\% last for less than a week, and hence brief febrile episodes cannot be used to exclude the diagnosis.

The size of this series allows, for the first time, an exploration of genotype-phenotype associations and also of the effect of patient age on disease features at presentation. Mutations affecting cysteine residues and the T50M variant were among the first identified in TRAPS. ${ }^{25}$ They have been widely regarded as associated with higher penetrance, a more severe disease phenotype and a high risk of AA amyloidosis. Our series includes 58 such patients and has found that a family history was no commoner in them than in other non-R92Q P46L sequence variants, but that their disease was more likely to persist into adulthood. No particular pattern of clinical features was commoner in patients with these sequence variants, and they did not appear to be over-represented among patients who developed AA amyloidosis.

Analysis of patients with the R92Q variant showed that these patients had a slightly different disease phenotype, with a lower proportion of familial disease, more headaches and fewer rash and eye manifestations. The lower percentage in adult patients with paediatric onset compared with both the children and patients who presented in adulthood, suggests that manifestation of R92Q-associated disease tends to be either as febrile attacks in children, which ameliorate as they mature, or as a genuinely later-onset disease. Both these clinical scenarios are consistent with a milder phenotype, ${ }^{26}$ and certainly no patients with R92Q have developed the most feared complication of TRAPS, AA amyloidosis. ${ }^{27}$ The role of low-penetrance variants in TRAPS disease aetiology has long been contentious. It remains possible that TNFRSF1A R92Q is simply acting as a modifier in patients with other, as yet, unidentified causes of an inflammatory phenotype. In this series 24 (44\%) patients had undergone sequencing of at least one other fever gene with only two cases found to carry the equally controversial MEFV sequence variants E148Q and R121Q, suggesting that we were not missing other common clear-cut inherited autoinflammatory conditions. The very high proportion of patients with R92Q in this series supports the view that R92Q-associated disease is a genuine phenomenon, although one that affects only a minority of carriers. Our results are more equivocal for P46L. We recruited only five patients; two of these were Caucasian but the other three were from populations with a known high gene carriage rate, one Arab and two of West African origin. It remains possible that their genetic findings are entirely incidental to their symptoms. Next-generation sequencing may help to clarify the significance of such common relatively low-penetrance variants. 
Table 5 Clinical manifestations reported in patients with TRAPS at disease presentation by age and mutation group

\begin{tabular}{|c|c|c|c|c|c|c|c|c|c|}
\hline Number of patients & $\begin{array}{l}\text { Whole TRAPS } \\
\text { population } \\
(\mathrm{n}=158) \\
\text { Number }(\%)\end{array}$ & $\begin{array}{l}\text { Pediatric } \\
\text { patients (A) } \\
(n=53) \\
\text { Number }(\%)\end{array}$ & $\begin{array}{l}\text { Adults with } \\
\text { pediatric onset (B) } \\
(\mathrm{n}=70) \\
\text { Number }(\%)\end{array}$ & $\begin{array}{l}\text { Adults with } \\
\text { adult onset (C) } \\
(n=35) \\
\text { Number (\%) }\end{array}$ & p Value* & $\begin{array}{l}\text { Cysteine or } \\
\text { T50M (D) } \\
(n=58) \\
\text { Number (\%) }\end{array}$ & $\begin{array}{l}\text { Other } \\
\text { mutations (E) } \\
(\mathrm{n}=39) \\
\text { Number (\%) }\end{array}$ & $\begin{array}{l}\text { Low-penetrance } \\
\text { mutations (F) } \\
(\mathrm{n}=59) \\
\text { Number }(\%)\end{array}$ & p Value* \\
\hline \multicolumn{10}{|l|}{ Mucocutaneous } \\
\hline Exudative pharyngitis & $5(3)$ & $3(6)$ & $1(1.5)$ & $1(3)$ & NS & $2(3)$ & 0 & $3(5)$ & NS \\
\hline Erythematous pharyngitis & $28(18)$ & $12(23)$ & $11(16)$ & $5(14)$ & NS & $7(12)$ & 7 (18) & $14(24)$ & NS \\
\hline Aphthous stomatitis & $15(9.5)$ & $7(13)$ & $4(6)$ & $4(11)$ & NS & $3(5)$ & $4(10)$ & $8(14)$ & NS \\
\hline Palpable purpura & $1(0.5)$ & $1(2)$ & 0 & 0 & NS & 0 & 0 & $1(2)$ & NS \\
\hline Maculopapular rash & $41(26)$ & $17(32)$ & $17(24)$ & $7(20)$ & NS & $14(24)$ & $15(38)$ & $12(20)$ & NS \\
\hline Urticarial rash & $39(25)$ & $12(23)$ & $20(29)$ & $7(20)$ & NS & $15(26)$ & $11(28)$ & $13(22)$ & NS \\
\hline Migratory rash & $28(18)$ & $9(17)$ & $16(23)$ & $3(9)$ & NS & $16(28)^{*}$ & 7 (18) & $5(8)$ & 0.01 \\
\hline Erysipelas-like erythema & $7(4)$ & $1(2)$ & $6(9)$ & 0 & 0.04 & $6(10) \dagger$ & 0 & $1(2)$ & 0.03 \\
\hline Localised erythema & $4(2.5)$ & $1(2)$ & $2(3)$ & $1(3)$ & NS & 0 & $2(5)$ & $2(3)$ & NS \\
\hline Generalised erythema & $3(2)$ & $1(2)$ & $1(1.5)$ & $1(3)$ & NS & 0 & $1(3)$ & $2(3)$ & NS \\
\hline Pseudo-folliculitis & $3(2)$ & $1(2)$ & $1(1.5)$ & $1(3)$ & NS & 0 & $1(3)$ & $2(3)$ & NS \\
\hline \multicolumn{10}{|l|}{ Musculoskeletal } \\
\hline Arthralgia & $101(64)$ & $34(64)$ & $48(69)$ & $19(54)$ & NS & $34(58)$ & $28(72)$ & $39(66)$ & NS \\
\hline Myalgia & $111(70)$ & $36(68)$ & $53(76)$ & $22(63)$ & NS & $43(74)$ & $29(74)$ & $39(66)$ & NS \\
\hline Myositis & $3(1.5)$ & $1(2)$ & $2(3)$ & 0 & NS & $3(5)$ & 0 & 0 & 0.04 \\
\hline Fasciitis & $6(4)$ & $0^{*}$ & $5(7)$ & $1(3)$ & 0.04 & $4(7)$ & $1(3)$ & $1(2)$ & NS \\
\hline Bone pain & $6(4)$ & $2(4)$ & $2(3)$ & $2(6)$ & NS & $2(3)$ & 0 & $4(7)$ & NS \\
\hline Monoarthritis & $9(6)$ & $4(8)$ & $2(3)$ & $2(4)$ & NS & $4(7)$ & $1(3)$ & $4(7)$ & NS \\
\hline Oligoarthritis & $15(9.5)$ & $2(4)$ & $9(13)$ & $4(11)$ & NS & $8(14)$ & $2(5)$ & $5(8)$ & NS \\
\hline Polyarthritis & $2(4)$ & $1(1.2)$ & $2(3)$ & $5(14)$ & 0.04 & $2(3)$ & $1(3)$ & $1(2)$ & NS \\
\hline \multicolumn{10}{|l|}{ Ocular } \\
\hline Periorbital oedema & $32(20)$ & $8(15)$ & $21(30)$ & $2(4)$ & NS & $14(24)$ & $8(20)$ & $10(17)$ & NS \\
\hline Periorbital pain & $20(13)$ & $6(11)$ & $10(14)$ & $4(11)$ & NS & $12(21)^{*}$ & $2(5)$ & $6(10)$ & 0.03 \\
\hline Conjunctivitis & $35(22)$ & $6(11)$ & $23(33)$ & $6(17)$ & NS & $18(31) \dagger$ & $17(44) \neq$ & $10(17)$ & 0.02 \\
\hline \multicolumn{10}{|l|}{ Gastrointestinal } \\
\hline Vomiting & $28(18)$ & $13(25)$ & $9(13)$ & $6(17)$ & NS & $6(10)$ & $7(18)$ & $15(26)$ & NS \\
\hline Abdominal pain & $110(70)$ & $38(72)$ & $53(76) \ddagger$ & $19(54)$ & 0.05 & $47(81)$ & $27(69)$ & $36(61)$ & NS \\
\hline Constipation & $21(13)$ & $2(3.8)^{*}+$ & $12(17)$ & $7(20)$ & 0.01 & $13(22)^{*}$ & $2(5)$ & $6(10)$ & 0.02 \\
\hline Diarrhoea & $28(18)$ & $12(23)$ & $10(14)$ & $6(17)$ & NS & $11(19)$ & 7 (18) & $10(17)$ & NS \\
\hline GI bleeding & $3(1.5)$ & 0 & $1(1.5)$ & $2(6)$ & NS & $3(5.1)$ & 0 & $1(2)$ & NS \\
\hline Aseptic peritonitis & $10(6)$ & 0 & $9(13)$ & $1(3)$ & 0.01 & $5(9)$ & $2(5)$ & $3(5)$ & NS \\
\hline \multicolumn{10}{|l|}{ Lymphoid organs } \\
\hline Generalised enlargement & $12(8)$ & $6(11)$ & $5(7)$ & $1(3)$ & NS & $5(9)$ & $3(8)$ & $4(7)$ & NS \\
\hline $\begin{array}{l}\text { Enlarged cervical lymph } \\
\text { nodes }\end{array}$ & $41(26)$ & $23(43)$ & $15(21)$ & $2(4)$ & 0.01 & $16(28)$ & $10(26)$ & $15(25)$ & NS \\
\hline Inguinal lymphadenopathy & $2(1)$ & $1(2)$ & 0 & $1(3)$ & NS & 0 & 0 & $2(3)$ & NS \\
\hline Lymph node pain & $21(13)$ & $10(19)$ & $10(14)$ & $1(3)$ & NS & $9(16)$ & $5(13)$ & $7(12)$ & NS \\
\hline Hepatomegaly & $9(6)$ & $5(9)$ & $4(6)$ & 0 & NS & $4(7)$ & $3(8)$ & $2(3)$ & NS \\
\hline
\end{tabular}




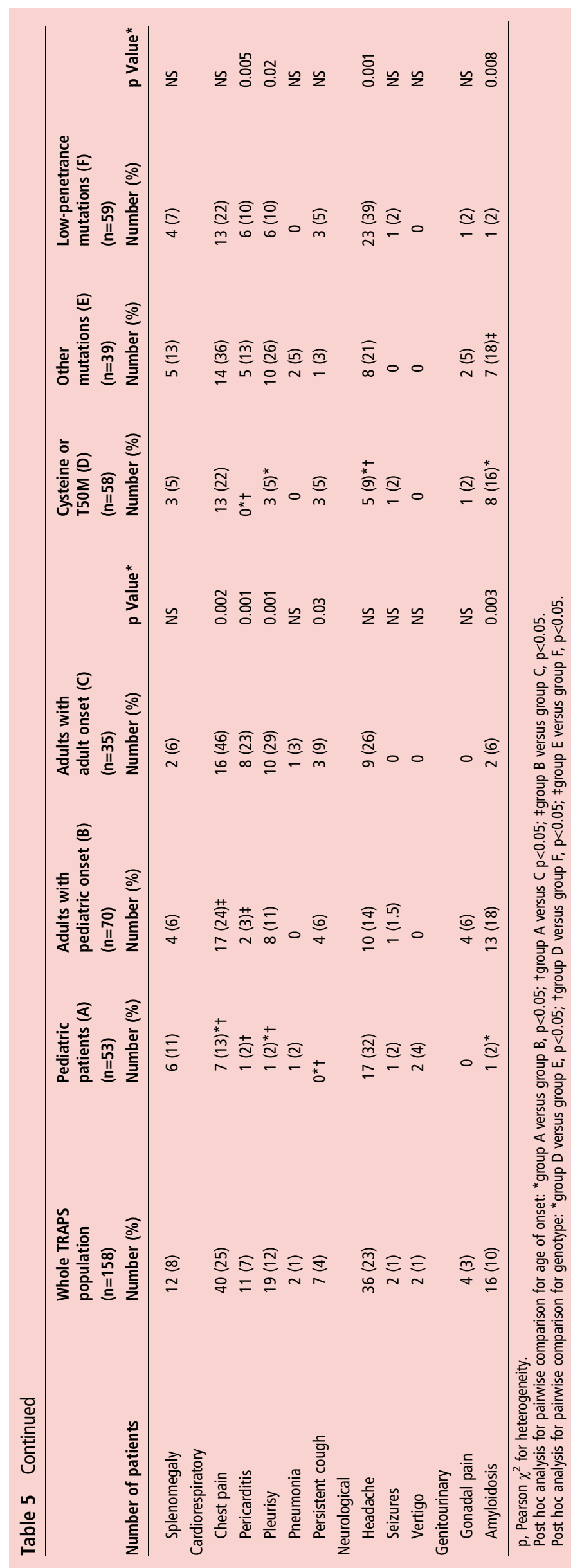

Although disease features seem to be similar in children and adults at presentation, there is a suggestion that some clinical manifestations, such as serositis, arthritis and constipation might be related to disease in adulthood (table 5).

Our study has a number of obvious limitations. Although multiple centres were involved most of these were specialist, and recruitment was unequally distributed, introducing a risk of geographical or centre-specific bias. The marked disparity in the number of patients from each country demonstrates this, since it seems very unlikely that TRAPS is several-fold more common in the UK and Italy. In addition this is a 'Eurocentric' cohort. TRAPS has been reported to occur in a wide spectrum of populations and given the large number of variants reported, the high rate of family-specific variants $(58 \%$ occurred in only one individual or family in this cohort) and absence of any postulated specific selective advantage in Europe, it seems likely that TRAPS occurs throughout the world and that variations between populations reflect ascertainment bias due a combination of lack of awareness of a rare condition and difficulties in accessing or financing genetic testing. Using rather limited ethnic groups to define TRAPS disease has potential drawbacks. The most obvious of these arises if rash is made a central component of the diagnostic criteria, particularly as the rashes seen in TRAPS are often evanescent and macular, therefore much more prominent on paler-skinned individuals. We also have some concerns that there may be bias in the selection of patients entered into this study favouring patients with more severe disease and perhaps also patients with systemic symptoms as isolated rash or abdominal pain may be managed without considering the diagnosis. This may be most evident in patients with the lower-penetrant variants where only patients with particularly severe features have been referred to specialist centres and our data may therefore reflect only the most severe end of the spectrum of R92Q-associated disease. In addition, two-thirds of the study group were adults at recruitment and their recollection of their disease at presentation might have been imprecise, especially in older adults recollecting childhood illness many decades earlier. ${ }^{26}$

Finally, although we report disease features at presentation here, other aims of the registry are to follow-up patients over the long term. This should allow description of treatment responses and long-term outcomes (both medical and socioeconomic), and also the opportunity to identify prognostic factors and raise disease awareness.

\section{Author affiliations}

${ }^{1}$ National Amyloidosis Centre, Royal Free Campus, University College Medical School, London, UK

${ }^{2}$ Pediatria II, Istituto Giannina Gaslini, Genova, Italy

${ }^{3}$ Pediatric Pneumology and Immunology, Charité-Universitätsmedizin Berlin, Berlin, Germany

${ }^{4}$ Biotechnology Research Laboratories, Amyloid Centre, Fondazione IRCCS Policlinico San Matteo, Pavia, Italy

${ }^{5}$ Unit of Autoinflammatory Diseases, CHU Montpellier, UM1, INSERM U844, Montpellier, France

${ }^{6}$ Rheumatology Unit, Policlinico le Scotte, University of Siena, Siena, Italy ${ }^{7}$ Department of Paediatrics, University Medical Center Utrecht, Utrecht, Netherlands ${ }^{8}$ Hospital Sant Joan de Déu, Universitat de Barcelona, Esplugues (Barcelona), Spain ${ }^{9}$ Centre de référence national des maladies auto-inflammatoires, CEREMAI,

rhumatologie pediatrique, CHU Le Kremlin Bicetre (University of Paris SUD, APHP), Le kremlin Bicetre (Paris), France

${ }^{10}$ Dipartimento di Pediatria, Unità di Immunologia e Reumatologia Pediatrica, Clinica Pediatrica dell'Università di Brescia, Spedali Civili, Brescia, Italy

${ }^{11}$ Unité d'Immunologie, Hématologie et Rhumatologie Pediatrique, Université ParisDescartes, Hôpital Necker-Enfants Malades, Centre de référence national pour les Arthrites Juveniles, APHP, IHU Imagine, Paris, France

${ }^{12}$ Reumatologia, Ospedale Pediatrico Bambin Gesù, Roma, Italy

${ }^{13}$ Service de pediatrie generale, Hopital A Mignot, Centre de référence national des 
maladies auto-inflammatoires, Le Chesnay (Paris), France

${ }^{14}$ Unidad De Reumatologia Pediatrica, Hospital Universitario La Paz, Madrid, Spain

${ }^{15}$ Reumatologia, Hospital Valle de Hebron, Barcelona, Spain

${ }^{16}$ Department of Allergology, Rheumatology and Clinical Immunology, University

Children's Hospital, University Medical Centre Ljubljana, Ljubljana, Slovenia

${ }^{17}$ Kinderkrankenhaus St. Marien, Landshut, Germany

${ }^{18}$ Department of Pediatric Nephrology and Rheumatology, Hacettepe University,

Ankara, Turkey

${ }^{19}$ Dept di Pediatria, Ospedale A Meyer, Firenze, Italy

${ }^{20}$ Rheumatology \& Immunology, Dr von Hauner Children's Hospital, Ludwig-

Maximilians-University Munich, Munich, Germany

${ }^{21}$ Center of Paediatric and Adolescent Rheumatology_ UCL, Institute of Child Health and Great Ormond Street Hospital NHS Foundation Trust, London, UK

${ }^{22}$ Istituto Giannina Gaslini, Pediatria II and Università degli Studi di Genova, Genova, Italy

Contributors HJL and MG: design and coordination of the study, data collection and paper writing. RP and PW: analysis of the data and manuscript revision. NR, AM: coordination of the study and manuscript editing. KG, LO, IT, LC, JF, JA, IK-P, $M C, B B-M, A I, V H, R M, C M, N T, R B, S O, R C, A J, P A B$ and PNH: data collection and manuscript revision.

Funding This project is supported by the Executive Agency for Health and Consumers of the European Union (EAHC, Project Nos 2007332 and 200923) and by Coordination Theme 1 (Health) of the European Community's FP7, grant agreement number HEALTH-F2-2008-200923. Unrestricted educational grants were also kindly provided by PRINTO and Novartis.

Competing interests None.

Ethics approval G Gaslini Institute institutional review board.

Provenance and peer review Not commissioned; externally peer reviewed.

Open Access This is an Open Access article distributed in accordance with the Creative Commons Attribution Non Commercial (CC BY-NC 3.0) license, which permits others to distribute, remix, adapt, build upon this work non-commercially, and license their derivative works on different terms, provided the original work is properly cited and the use is non-commercial. See: http://creativecommons.org/ licenses/by-nc/3.0/

\section{REFERENCES}

1 Williamson LM, Hull D, Mehta R, et al. Familial Hibernian fever. Q J Med. 1982;51:469-80.

2 McDermott MF. Autosomal dominant recurrent fevers. Clinical and genetic aspects. Rev Rhum [Engl Ed] 1999;66:484-91.

3 Aganna E, Hammond L, Hawkins PN, et al. Heterogeneity among patients with tumor necrosis factor receptor-associated periodic syndrome phenotypes. Arthritis Rheum 2003;48:2632-44.

4 McGonagle D, McDermott MF. A proposed classification of the immunological diseases. PLoS Medicine 2006;3:1242-8.

5 Hull KM, Drewe E, Aksentijevich I, et al. The TNF receptor-associated periodic syndrome (TRAPS): emerging concepts of an autoinflammatory disorder. Medicine (Baltimore) 2002;81:349-68.

6 Milhavet F, Cuisset L, Hoffman HM, et al. The infevers autoinflammatory mutation online registry: update with new genes and functions. Hum Mutat 2008;29:803-8.

7 Touitou I, Lesage S, McDermott M, et al. Infevers: an evolving mutation database for auto-inflammatory syndromes. Hum Mutat 2004;24:194-8.

8 Sarrauste de Menthiere C, Terriere S, Pugnere D, et al. INFEVERS: the Registry for FMF and hereditary inflammatory disorders mutations. Nucleic Acids Res 2003;31:282-5.

9 Rebelo SL, Bainbridge SE, Amel-Kashipaz MR, et al. Modeling of tumor necrosis factor receptor superfamily $1 \mathrm{~A}$ mutants associated with tumor necrosis factor receptor-associated periodic syndrome indicates misfolding consistent with abnormal function. Arthritis Rheum 2006;54:2674-87

10 Todd I, Radford PM, Daffa N, et al. Mutant tumor necrosis factor receptor associated with tumor necrosis factor receptor-associated periodic syndrome is altered antigenically and is retained within patients' leukocytes. Arthritis Rheum 2007;56:2765-73.

11 Nedjai B, Hitman GA, Yousaf N, et al. Abnormal tumor necrosis factor receptor I cell surface expression and NF- $\mathrm{KB}$ activation in tumor necrosis factor receptor-associated periodic syndrome. Arthritis Rheum 2008;58:273-83.

12 Bachetti T, Chiesa S, Castagnola P, et al. Autophagy contributes to inflammation in patients with TNFR-associated periodic syndrome (TRAPS). Ann Rheum Dis 2013;72:1044-52. Epub 2012/11/03.

13 Simon A, Park H, Maddipati R, et al. Concerted action of wild-type and mutant TNF receptors enhances inflammation in TNF receptor 1-associated periodic fever syndrome. Proc Natl Acad Sci USA 2010;107:9801-6.

14 Ravet N, Rouaghe S, Dode C, et al. Clinical significance of P46L and R92Q substitutions in the tumour necrosis factor superfamily $1 \mathrm{~A}$ gene. Ann Rheum Dis 2006;65:1158-62.

15 Kumpfel T, Hohlfeld R. Multiple sclerosis. TNFRSF1A, TRAPS and multiple sclerosis. Nat Rev Neurol 2009;5:528-9.

16 Lainka E, Neudorf U, Lohse P, et al. Incidence of TNFRSF1A mutations in German children: epidemiological, clinical and genetic characteristics. Rheumatology (Oxford) 2009:48:987-91.

17 Kallinich T, Gattorno M, Grattan CE, et al. Unexplained recurrent fever: when is autoinflammation the explanation? Allergy 2013;68:285-96.

18 Toplak N, Frenkel J, Ozen $\mathrm{S}$, et al. An international registry on autoinflammatory diseases: the Eurofever experience. Ann Rheum Dis 2012;71:1177-82. Epub 2012/ 03/02.

19 Ter Haar N, Lachmann H, Ozen S, et al. Treatment of autoinflammatory diseases: results from the Eurofever Registry and a literature review. Ann Rheum Dis 2013;72:678-85. Epub 2012/07/04.

20 Haas SL, Lohse P, Schmitt WH, et al. Severe TNF receptor-associated periodic syndrome due to 2 TNFRSF1A mutations including a new F60V substitution. Gastroenterology 2006;130:172-8. eng.

21 Rosen-Wolff A, Kreth HW, Hofmann S, et al. Periodic fever (TRAPS) caused by mutations in the TNFalpha receptor 1 (TNFRSF1A) gene of three German patients. Eur JHaematol 2001;67:105-9. eng.

22 Stojanov S, Dejaco C, Lohse $\mathrm{P}$, et al. Clinical and functional characterisation of a novel TNFRSF1A c.605T>A/V173D cleavage site mutation associated with tumour necrosis factor receptor-associated periodic fever syndrome (TRAPS), cardiovascular complications and excellent response to etanercept treatment. Ann Rheum Dis 2008;67:1292-8

23 McDermott MF, Aksentijevich I, Galon J, et al. Germline mutations in the extracellular domains of the $55 \mathrm{kDa}$ TNF receptor, TNFR1, define a family of dominantly inherited autoinflammatory syndromes. Cell 1999;97:

133-44.

24 Drewe E, McDermott EM, Powell PT, et al. Prospective study of anti-tumour necrosis factor receptor superfamily $1 \mathrm{~B}$ fusion protein, and case study of anti-tumour necrosis factor receptor superfamily 1 A fusion protein, in tumour necrosis factor receptor associated periodic syndrome (TRAPS): clinical and laboratory findings in a series of seven patients. Rheumatology (Oxford) 2003;42:235-9.

25 McDermott MF, Aganna E, Hitman GA, et al. An autosomal dominant periodic feve associated with $\mathrm{AA}$ amyloidosis in a north Indian family maps to distal chromosome 1q. Arthritis Rheum 2000;43:2034-40.

26 Pelagatti MA, Meini A, Caorsi R, et al. Long-term clinical profile of children with the low-penetrance R92Q mutation of the TNFRSF1A gene. Arthritis Rheum 2011;63:1141-50.

27 Aksentijevich I, Galon J, Soares M, et al. The tumor-necrosis-factor receptor-associated periodic syndrome: new mutations in TNFRSF1A, ancestral origins, genotype-phenotype studies, and evidence for further genetic heterogeneity of periodic fevers. Am J Hum Genet 2001;69:301-14. 